\title{
PRESENTACIÓN
}

\section{La epidemia de tabaquismo. Epidemiología, factores de riesgo y medidas de prevención}

\author{
Eduardo C Lazcano-Ponce, ${ }^{(1)}$ Mauricio Hernández-A vila. ${ }^{(2)}$
}

$\mathrm{N}$

os complace presentar el número especial titulado

"La epidemia de tabaquismo. Epidemiología, factores de riesgo y medidas de prevención". En esta edición participan grupos multidisciplinarios de investigadores nacionales y extranjeros que brindan información actualizada sobre la epidemiología descriptiva de la epidemia de tabaquismo, los factores de riesgo, su fracción atribuible, los daños a la salud ocasionados por esta exposición, el impacto económico de su consumo, así como las perspectivas de prevención y tratamiento. Adicionalmente, se incluyen artículos especiales que han tenido gran relevancia y han influido grandemente en las políticas de salud establecidas contra este hábito.

La información contenida en este número especial será de gran utilidad para las sociedades, gobiernos y grupos de investigación que elaboran programas de cesación del consumo de tabaco. El impacto de esta exposición es elocuente: cuatro millones de muertes innecesarias por año, atribuidas a consumo de tabaco en el mundo, que representan actualmente $11 \mathrm{mil}$ muertes cada día. Para el año 2020 se estiman 10 millones de muertes anuales originadas por consumo de tabaco, si se mantuviera el mismo patrón de exposición. Asimismo, la proporción atribuible del total de muertes en regiones industrializadas ha llegado a estimarse hasta en $14.5 \%$.

Los efectos a la salud atribuidos al humo de tabaco han sido ampliamente descritos en la literatura científica. El tabaquismo se ha asociado fuertemente con diversos tipos de cáncer, particularmente de origen epitelial, enfermedad cardiovascular, enfermedad pulmonar obstructiva crónica, fracturas, osteoporosis, enfermedad vascular periférica y patologías tiroideas. Recientemente, se ha estimado que el antecedente de fumar más de 25 cigarrillos diarios incrementa dos veces el riesgo de diabetes mellitus. Asimismo, los daños a la salud de la mujer son importantes; destacan el bajo peso al nacer y en algunos casos la infertilidad. Asimismo, el tabaquismo pasivo tiene efectos sobre la salud de los niños.

En términos del impacto en mortalidad regional, en Canadá y Estados Unidos de América (EUA) anualmente se estiman carca de 604000 muertes en comparación con las 168000 del resto de los países de América. A pesar de estas cifras, el consumo de tabaco ha declinado en países desarrollados y se ha incrementado rápidamente en países en desarrollo, principalmente en Asia y Latinoamérica.

En este contexto, no existe duda de que la epidemia de tabaquismo en el ámbito mundial, particularmente en países en desarrollo, constituye uno de los principales problemas de salud pública y México no es la excepción. Por esta razón, este número tiene singular importancia porque presenta evidencias de investigaciones originales, acerca no sólo del estado actual de la epidemia de tabaquismo, sino de la necesidad de establecer estrategias de investigación-acción en diversos contextos para fomentar ambientes libres de humo de tabaco.

(1) Dirección de Investigación en Enfermedades Crónicas. Centro de Investigación en Salud Poblacional. Instituto N acional de Salud Pública. Cuernavaca, Morelos, México.

(2) Centro de Investigación en Salud Poblacional. Instituto N acional de Salud Pública. Cuernavaca, Morelos. México. 
Actualmente los estados reconocen que los productos del tabaco son nocivos y que el consumo de los mismos causa daños a la salud. Se empiezan a establecer planteamientos relativos a la responsabilidad y la indemnización relacionadas con el consumo de productos de tabaco.

Asimismo, se reconoce que el comercio ilegal de productos de tabaco afecta a la economía y los ingresos fiscales, lo que provoca menores ingresos financieros y la consecuente menor inversión en programas de salud, particularmente en la lucha antitabaco. Por esta razón, acuerdos y acciones legales en los ámbitos nacional e internacional se constituyen como necesarios para combatir este tipo de exposición.

La experiencia de los países en la reducción del consumo de tabaco es muy limitada y con escaso impacto, pero algunas de las medidas que se tratan de desarrollar están orientadas hacia a) la prohibición. Este hecho se sustenta en la afirmación de que el problema del tabaquismo no es el consumo, sino su producción; b) restricción del acceso de los jóvenes al tabaco. Esta acción es difícil de establecer porque los jóvenes obtienen los cigarrillos de sus pares con mayor edad y en algunos casos de sus padres; c) sustitución y diversificación de cultivos. A este respecto, cerca de $90 \%$ de la producción es obtenida de 20 países, principalmente de China (42\%), EUA, India y Brasil (juntos representan 24\%); d) incremento de aranceles e impuestos; e) restricciones al comercio internacional; f) necesidad de establecer firmes acciones contra el contrabando (se estiman cerca de 355 billones de cigarrillos en el mercado negro).

Finalmente, existe todavía muy poca experiencia en la investigación de la efectividad de diversas acciones preventivas contra el consumo de tabaco. Por esta razón, este número especial brinda una información valiosa, obtenida de trabajos originales, que será de utilidad para coadyuvar a combatir la exposición que produce mayor daño a la salud en el ámbito mundial: el tabaquismo. 